\title{
Impairment of Mossy Fiber Long-Term Potentiation and Associative Learning in Pituitary Adenylate Cyclase Activating Polypeptide Type I Receptor-Deficient Mice
}

\author{
Christiane Otto, ${ }^{1}$ Yury Kovalchuk, ${ }^{3}$ David Paul Wolfer, ${ }^{4}$ Peter Gass, ${ }^{1,5}$ Miguel Martin, ${ }^{6}$ Werner Zuschratter, ${ }^{7}$ \\ Hermann Josef Gröne, ${ }^{2}$ Christoph Kellendonk, ${ }^{1,8}$ François Tronche,, ${ }^{1}$ Rafael Maldonado, ${ }^{6}$ Hans-Peter Lipp, ${ }^{4}$ \\ Arthur Konnerth, ${ }^{3}$ and Günther Schütz ${ }^{1}$

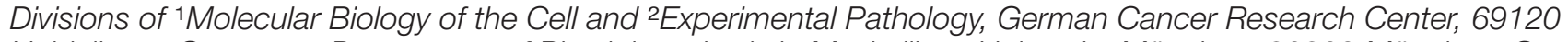 \\ Heidelberg, Germany, 3Department of Physiology, Ludwig Maximilians University München, 80802 München, Germany, \\ 4/nstitute of Anatomy, University of Zürich, 8057 Zürich, Switzerland, ${ }^{5}$ Central Institute of Mental Health, 68159 \\ Mannheim, Germany, ${ }^{6}$ Department of Neuropharmacology, University Pompeu Fabra, 08003 Barcelona, Spain, ${ }^{7}$ Leibniz \\ Institute for Neurobiology, 39118 Magdeburg, Germany, and ${ }^{8}$ Center for Neurobiology and Behavior, Howard Hughes \\ Medical Institute, Columbia University, New York, New York 10032
}

The pituitary adenylate cyclase activating polypeptide (PACAP) type I receptor (PAC1) is a G-protein-coupled receptor binding the strongly conserved neuropeptide PACAP with 1000-fold higher affinity than the related peptide vasoactive intestinal peptide. PAC1-mediated signaling has been implicated in neuronal differentiation and synaptic plasticity. To gain further insight into the biological significance of PAC1-mediated signaling in vivo, we generated two different mutant mouse strains, harboring either a complete or a forebrain-specific inactivation of PAC1.

Mutants from both strains show a deficit in contextual fear conditioning, a hippocampus-dependent associative learning paradigm. In sharp contrast, amygdala-dependent cued fear conditioning remains intact. Interestingly, no deficits in other hippocampus-dependent tasks modeling declarative learning such as the Morris water maze or the social transmission of food preference are observed. At the cellular level, the deficit in hippocampus-dependent associative learning is accompanied by an impairment of mossy fiber long-term potentiation (LTP). Because the hippocampal expression of PAC1 is restricted to mossy fiber terminals, we conclude that presynaptic PAC1mediated signaling at the mossy fiber synapse is involved in both LTP and hippocampus-dependent associative learning.

Key words: PACAP type I receptor; knock-out mice; fear conditioning; synaptic plasticity; LTP; mossy fiber
The pituitary adenylate cyclase activating polypeptide (PACAP) type I receptor PAC1 is a G-protein-coupled receptor that can activate several second messengers, most importantly the adenylate cyclase-protein kinase A (PKA) signal transduction pathway (Christophe, 1993). PAC1 binds the strongly conserved neuropeptide PACAP with a 1000-fold higher affinity than its related peptide vasoactive intestinal peptide (VIP) (Shivers et al., 1991). Unlike PACAP type II receptors VPAC1 and VPAC2, which are strongly expressed in peripheral tissues such as lung, liver, and the gastrointestinal tract (Ishihara et al., 1992; Lutz et al., 1993), PAC1 is predominantly expressed in the CNS. Especially the neocortex, the limbic system, and the brainstem exhibit a strong expression of PAC1 mRNA (Hashimoto et al., 1996a; Otto et al., 1999). PAC1 has been implicated in neurotransmission, neurotrophic actions, neuronal differentiation, and synaptic plasticity (Arimura, 1998). Interestingly, within the hippocampus, PAC1 expression is restricted to the granule cells of the dentate gyrus,

\footnotetext{
Received Dec. 5, 2000; revised May 7, 2001; accepted May 8, 2001.

This work was supported by the European Commission, the Deutsche Forschungsgemeinschaft, the Fonds der Chemischen Industrie, the Bundesministerium für Bildung und Forschung, and the Volkswagenstiftung. We are grateful to $\mathrm{H}$. Kern, A. Klewe-Nebenius, K. Anlag, R. Klären, and I. Bortfeldt for technical assistance and to Dr. T. Mantamadiotis for carefully reading this manuscript.

Correspondence should be addressed to Dr. Günther Schütz, Molekularbiologie der Zelle, Im Neuenheimer Feld 280, 69120 Heidelberg, Germany. E-mail: g.schuetz@dkfz-heidelberg.de.

Copyright (C) 2001 Society for Neuroscience 0270-6474/01/215520-08\$15.00/0
}

and the PAC1 protein is localized presynaptically in hippocampal mossy fiber terminals (Otto et al., 1999). There is, thus, a remarkable coincidence of the presynaptic expression of PAC1 and the well established role of calcium and cAMP in synaptic transmission and long-term potentiation (LTP) at hippocampal mossy fiber terminals (Huang et al., 1994; Weisskopf et al., 1994). This coincidence and the finding that Drosophila harboring a mutation in the PACAP-related gene amnesiac display deficits in associative learning (Quinn et al., 1979) suggest a possible role of PAC1 in learning and memory.

Two types of information storage have been identified in the mammalian brain: declarative and nondeclarative memory and learning. In contrast to the phylogenetically younger declarative learning, associative learning (a subtype of nondeclarative learning) is already well developed in invertebrates (Milner et al., 1998). The hippocampus seems to play a pivotal role in the generation of long-term memory in almost all declarative (Milner et al., 1998) paradigms and at least one associative learning model, i.e., contextual fear conditioning (Kim and Fanselow, 1992; Philips and LeDoux, 1992). It is generally accepted, although not yet formally demonstrated, that activity-dependent long-lasting changes in synaptic strength, particularly LTP, represent the cellular basis for the consolidation of long-term memory (Swanson et al., 1982). Within the hippocampus three types of excitatory synapses using glutamate as neurotransmitter are known: the perforant-path synapse, the mossy fiber synapse, and 
the Schaffer collateral. LTP at the Schaffer collateral and the perforant path synapses is initiated postsynaptically by an activation of NMDA receptors, which leads to a postsynaptic calcium rise and activation of calcium-calmodulin-dependent kinase II (Bliss and Collingridge, 1993). LTP at the mossy fiber synapse is distinctly different from LTP at the other hippocampal synapses. It is NMDA receptor-independent and requires a presynaptic calcium rise (Nicoll and Malenka, 1995), which leads via calmodulin to an activation of adenylate cyclases and PKA (Huang et al., 1994; Weisskopf et al., 1994). To address the role of PAC1mediated signaling in synaptic plasticity and learning and memory, we generated two different mutant mouse lines harboring either a complete or a forebrain-specific inactivation of PAC1.

\section{MATERIALS AND METHODS}

Generation of mice. We modified the PAC1 locus in embryonic stem (ES) cells (ET14/1) as described (Gu et al., 1994). The targeting vector was constructed from isogenic DNA (Kaestner et al., 1994). The upstream loxP site, together with an additional $X b a \mathrm{I}$ site was introduced into the intron preceding exon 11 using overlap PCR. The targeting vector

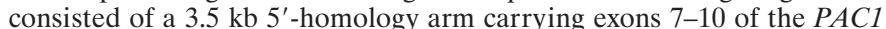
gene, followed by a $0.35 \mathrm{~kb} B a m \mathrm{HI} / H i n d I I I$ fragment encompassing the upstream loxP site and exon 11. The selection cassette flanked by two loxP sites was introduced downstream of the BamHI/HindIII fragment. The $3^{\prime}$-homology arm was a $4.5 \mathrm{~kb}$ HindIII fragment. After transfection of ES cells, G418-resistent clones were analyzed by Southern blot using probes from outside the homology arms. Homologously recombined clones (frequency of homologous recombination was $12 \%$ ) were transiently transfected with a Cre expression plasmid $(20 \mu \mathrm{g})$, and subclones were selected in the presence of gancyclovir $(1 \mu \mathrm{M})$. Mice carrying the $P A C 1^{-}$ or $P A C 1^{\text {loxP }}$ allele were derived by blastocyst injection.

For generation of CaMKCre 2 mice, nlsCre has been cloned into a CaMKII $\alpha$-vector, as described previously (Kellendonk et al., 1999). Linearized pMM403-Cre insert DNA was injected into the pronuclei of C57BL/6 oocytes, and several transgenic lines were obtained. In the CaMKCre2 line, Cre recombinase expression pattern was defined using an anti-Cre recombinase antibody (Kellendonk et al., 1999). In $30 \%$ of the $P A C$ CaMKCre2 mice, mosaic inactivation of the Cre recombinase transgene was observed. Those mice were identified postmortem immunohistochemically and excluded from the results.

RNase protection analysis and in situ hybridization. RNase protection analysis and in situ hybridization were performed as described previously (Otto et al., 1999). Probes used in RNase protection analysis were: PAC1 [nucleotides (nt) 637-1037 of the murine PAC1 cDNA] (Hashimoto et al., 1996b), VPAC1 (nt 1-232 of the murine VPAC1 cDNA) (Johnson et al., 1996), and VPAC2 (nt 106-446 of the murine VPAC2 cDNA) (Inagaki et al., 1994).

Electrophysiology. Hippocampal slices (300 $\mu \mathrm{m}$ thick) were prepared from 4- to 6-week-old mice. Slices were incubated at $33^{\circ} \mathrm{C}$ in oxygenated standard solution for at least $1 \mathrm{hr}$ before transferring them into the recording chamber. The standard solution contained (in $\mathrm{mm}$ ): $125 \mathrm{NaCl}$, 2.5 or $3.5 \mathrm{KCl}, 2 \mathrm{CaCl}_{2}, 1.2 \mathrm{MgCl}_{2}, 1.25 \mathrm{NaH}_{2} \mathrm{PO}_{4}, 26 \mathrm{NaHCO}_{3}$, and 20 glucose, bubbled with $95 \% \mathrm{O}_{2}$ and $5 \% \mathrm{CO}_{2}$. Whole-cell recordings were performed in the presence of bicuculline $(10 \mu \mathrm{M})$. For the recordings of EPSCs at mossy fiber synapses (MF-EPSCs), the concentration of $\mathrm{CaCl}_{2}$ was raised to $3 \mathrm{~mm}$, and $100 \mu \mathrm{M}$ DL-AP-5 and $0.3 \mu \mathrm{M}$ CNQX were added to prevent epileptiform activity. The MF-EPSCs were recorded at a holding potential of $-70 \mathrm{mV}$. During the test period, mossy fibers were stimulated every $20 \mathrm{sec}$ using glass pipettes (containing $1 \mathrm{M} \mathrm{NaCl}$ ) that were placed in stratum lucidum. LTP of the MF-EPSC was produced by a train lasting $5 \mathrm{sec}$ at $25 \mathrm{~Hz}$, administered at control stimulus intensity (Castillo et al., 1997). At the end of the recordings $\left(2 S, 1^{\prime} R, 2^{\prime} R, 3^{\prime} R\right)-2$ (2,3-dicarboxycyclopropyl)-glycine (DCG-IV; $1 \mu \mathrm{M}$ ), a specific agonist of the metabotropic glutamate receptors (mGluRs) of the group 2/3 subtype specifically expressed in mossy fiber terminals but not at associationalcommissural synapses (Yokoi et al., 1996; Castillo et al., 1997), was added to the bath to assess the mossy fiber component of the recorded EPSC. In addition, MF inputs were identified by their distinct properties concerning paired-pulse facilitation (PPF), frequency facilitation and the fast rise time of the EPSCs (Claiborne et al., 1993; Salin et al., 1996; Yeckel et al., 1999). To evoke EPSCs in the granule cells, the glass electrode was positioned in the outer third of the molecular layer of the dentate gyrus, thereby stimulating preferentially the lateral perforant path (LPP). The test stimuli were delivered every $15 \mathrm{sec}$, and the EPSCs were recorded at a holding potential of -70 to $-80 \mathrm{mV}$. LTP was induced by five bursts of stimuli $(10 \mathrm{sec}$ at $100 \mathrm{~Hz})$ delivered at interval of $15 \mathrm{sec}$, whereas the whole-cell amplifier was switched to the currentclamp mode, and the holding voltage was set to $-50 \mathrm{mV}$.

Whole-cell recordings were performed using an EPC-9 patch-clamp amplifier (Heka, Lambrecht, Germany) The pipette solution contained (in mM): $140 \mathrm{~K}$-gluconate, $10 \mathrm{NaCl}, 2 \mathrm{Mg}$-ATP, $2 \mathrm{Na}_{2}$-ATP, $0.4 \mathrm{Na}_{2}-$ GTP, 10 K-HEPES, 10 phosphocreatine, and 0.1 Oregon Green 488 BAPTA-1. The pH was adjusted to 7.3 with $\mathrm{KOH}$. The fluorescent indicator Oregon Green 488 BAPTA-1 was included to acquire confocal images of the recorded CA3 pyramidal cells, confirming their identity. The pipette resistance ranged from 3.5 to $7.5 \mathrm{M} \Omega$, and the series resistance from 11 to $25 \mathrm{M} \Omega$ for recording from CA3 cells and 25 to 50 $\mathrm{M} \Omega$ for recordings from granule cells. No series resistance compensation was applied. The recordings from the granule cells with a series resistance $<25 \mathrm{M} \Omega$ were discarded for the reason that the induction of LTP was not reliable, perhaps reflecting the "washout of LTP" in whole-cell configuration. The experiments were performed either at room temperature $\left[21-25^{\circ} \mathrm{C}\right.$; MF-LTP, MF-PPF, and MF- post-tetanic potentiation (PTP)] or at $30-32^{\circ} \mathrm{C}$ (PP-LTP). PPF was defined as the percentage ratio of the EPSC in response to the second versus that obtained with the first stimulus. The interstimulus interval was $60 \mathrm{msec}$. PTP was measured as a ratio of the mean EPSC amplitude averaged over the first minute after the conditioning tetanus and the mean amplitude of the control EPSC recorded before the tetanic stimulation.

Behavioral studies. We matched mutant and control mice for sex and age and housed littermates together. Data were analyzed by Student's $t$ test, and results are depicted as mean \pm SEM. For direct comparison of both mutant mouse strains, all experiments of this study were performed on the same genetic background, i.e., $75 \%$ C57BL/6/25\% 129 Ola.

Social transmission of food preference. The social transmission of food preference was performed as described previously (Gass et al., 1998). Training and testing of mice was comprised of three main stages. First, a demonstrator mouse was allowed to eat powdered ground chow scented with either cinnamon $(1 \% \mathrm{w} / \mathrm{w})$ or cocoa $(2 \% \mathrm{w} / \mathrm{w})$. Second, the demonstrator mouse and littermate observer mice (memory-tested mice) were allowed to freely interact for $10 \mathrm{~min}$. In the third phase, observer mice were tested for food preference $24 \mathrm{hr}$ after the interaction session. Each mouse was given a free choice between two food cups with cinnamon or cocoa, respectively, for $2 \mathrm{hr}$. Afterward, the amounts of cued and noncued food eaten were determined.

Morris water maze. A white Plexiglas circular pool of $150 \mathrm{~cm}$ diameter and $50 \mathrm{~cm}$ height was filled with water $\left(16 \mathrm{~cm}\right.$ deep, $\left.24-26^{\circ} \mathrm{C}\right)$ and made opaque by the addition of milk (Gass et al., 1998). Distant visual cues for navigation were available on the walls of the room illuminated by diffuse light (12 lux). A wire mesh platform $(16 \times 16 \mathrm{~cm})$ was placed $0.5 \mathrm{~cm}$ below the water surface, at $35 \mathrm{~cm}$ from the wall of the pool. The swim paths of the mice were recorded using a video camera suspended above the center of the pool and were fed to an electronic imaging system recording the $x-y$ coordinates (Noldus EthoVision 1.90). The recorded paths were analyzed as described previously (Gass et al., 1998). During the acquisition phase, animals had two training trials per day (with an interval of $1 \mathrm{~min}$ ) over a period of 14 consecutive days. The $1 \mathrm{~min}$ intertrial interval was spent on the platform. If an animal did not find the platform in the first trial, it was placed on it after $1 \mathrm{~min}$. The probe trial (free swimming without the platform in the pool) was performed on days 10 and 15. Data were analyzed by a repeated two-way ANOVA.

Fear conditioning. The conditioning system (TSE, Bad Homburg, Germany) consisted of a soundproof box $(58 \times 30 \times 27 \mathrm{~cm})$ with a gray interior, a $12 \mathrm{~V}$ light at the ceiling, and a Plexiglas chamber $(35 \times 20 \times$ $20 \mathrm{~cm}$ ) that was placed on a shock grid made from stainless steel rods (Gass et al., 1998). The grid was connected to a shocker-scrambler unit delivering shocks of defined duration and intensity. For both contextual and cued conditioning, mice were placed into the Plexiglas chamber for 2 min before the onset of a discrete conditioned stimulus $(2800 \mathrm{~Hz}$ tone; $85 \mathrm{~dB}$ ) that lasted $30 \mathrm{sec}$. At the end of the tone, animals were subjected to the unconditioned stimulus ( $2 \mathrm{sec}$ of continuous footshock at $0.8 \mathrm{~mA}$ ). Animals were left in the conditioning chamber for another $30 \mathrm{sec}$ and were then placed back into their home cages. Twenty-four hours after training, conditioning was assessed by measuring freezing, defined as a complete lack of movement besides respiration. For contextual conditioning, freezing was measured for $5 \mathrm{~min}$ in the same chamber in which the animals were trained. For the analysis of cued conditioning, animals 
were placed in a novel context (triangular cage with nongrid floor and lemon smell). Two minutes later, the tone started for a period of $3 \mathrm{~min}$ during which freezing was assessed. Freezing was scored in $10 \mathrm{sec}$ intervals, and the score was calculated in percentage of total observation time.

\section{RESULTS}

Generation of two different PAC1-deficient mouse lines

To disrupt $P A C 1$ in vivo, we developed two different mutant mouse lines using the Cre/loxP recombination system ( $\mathrm{Gu}$ et al., 1994). To inactivate all splice variants of $P A C 1$ known so far, we targeted exon 11 encoding the largest part of transmembrane domain IV of the receptor protein (Arimura, 1998). After homologous recombination in ES cells, we generated two different $P A C 1$ alleles (Fig. 1a). The $P A C 1^{-}$allele lacking exon 11 was injected into blastocysts to generate $\mathrm{PAC} 1^{-/-}$mice with an ubiquitous inactivation of $P A C 1$. In the $P A C 1^{\text {lox } P}$ allele, exon 11 was flanked by two loxP recognition sites (Fig. 1a) for Cre recombinase-mediated excision of the intervening DNA sequence. $P A C 1^{\operatorname{lox} P}$ will therefore be inactivated in any cell expressing the recombinase. Mice homozygous for $P A C 1^{l o x P}$ appear normal and expression of PAC1 mRNA is identical to that of wild-type mice (data not shown). For generation of mutant mice with a forebrain-specific inactivation of PAC1 $\left(P A C 1^{\text {loxP }} /\right.$ loxPCaMKCre2, abbreviated $\left.\mathrm{PAC} 1^{\mathrm{CaMKCre} 2}\right), \mathrm{PAC}^{\text {loxP }}$ mice were bred with transgenic mice (CaMKCre2 mice) expressing the Cre recombinase under the control of the $\mathrm{CaMKII} \alpha$ promoter. In this transgenic CaMKCre2 line, Cre recombinase expression is restricted to the olfactory bulbs, cortical forebrain areas, and the hippocampus. Within the striatum very few scattered neurons express the Cre recombinase, whereas no expression is detected in the thalamus, the amygdala, the midbrain, the hindbrain, and the cerebellum (data not shown).

According to the expression pattern of the Cre recombinase, $\mathrm{PAC1}{ }^{\mathrm{CaMKCre} 2}$ mice show an inactivation of $P A C 1$ in three brain areas, the olfactory bulbs, the cortical areas of the forebrain (data not shown), and the dentate gyrus (Fig. 1f). Conversely, $\mathrm{PAC1}^{-/-}$mice show an ubiquitous inactivation of $P A C 1$. Wildtype transcripts of $P A C 1$ are completely absent (Fig. 1b,e). Instead, an alternatively spliced transcript reaching $8 \%$ of the wild-type RNA levels is detectable in $\mathrm{PAC} 1^{-1-}$ brains (Fig. 1b). Sequencing of this transcript reveals alternative splicing from exon 10-12, leading to a frame shift with subsequent stop codon (data not shown) and resulting in a truncated receptor molecule that because of the absence of the third intracellular loop cannot couple to G-proteins any longer. Interestingly, the other known PACAP receptors $V P A C 1$ and $V P A C 2$, belonging to the class of PACAP type II receptors, are not upregulated in $\mathrm{PAC} 1^{-/-}$mice (Fig. 1c).

At the age of weaning, PAC1 $1^{\mathrm{CaMKCre} 2}$ mice are found at the expected Mendelian ratio $(n=381)$, whereas $\mathrm{PAC} 1^{-1-}$ mice are found at a frequency of $19 \%$ instead of $25 \%(n=589)$. Both types of mutants are fertile, appear healthy, and are indistinguishable from their wild-type littermates. Histological analysis of organs from both mutant mouse lines does not reveal any pathological abnormalities (data not shown). Especially within the hippocampal formation neither neuronal proliferation nor differentiation defects nor mossy fiber abnormalities are observed (data not shown). A neurological examination including testing on a hot plate as well as testing of reflexes, motoric strength, and coordination (rotarod) does not reveal any deficits in sensory or motor abilities (data not shown). a
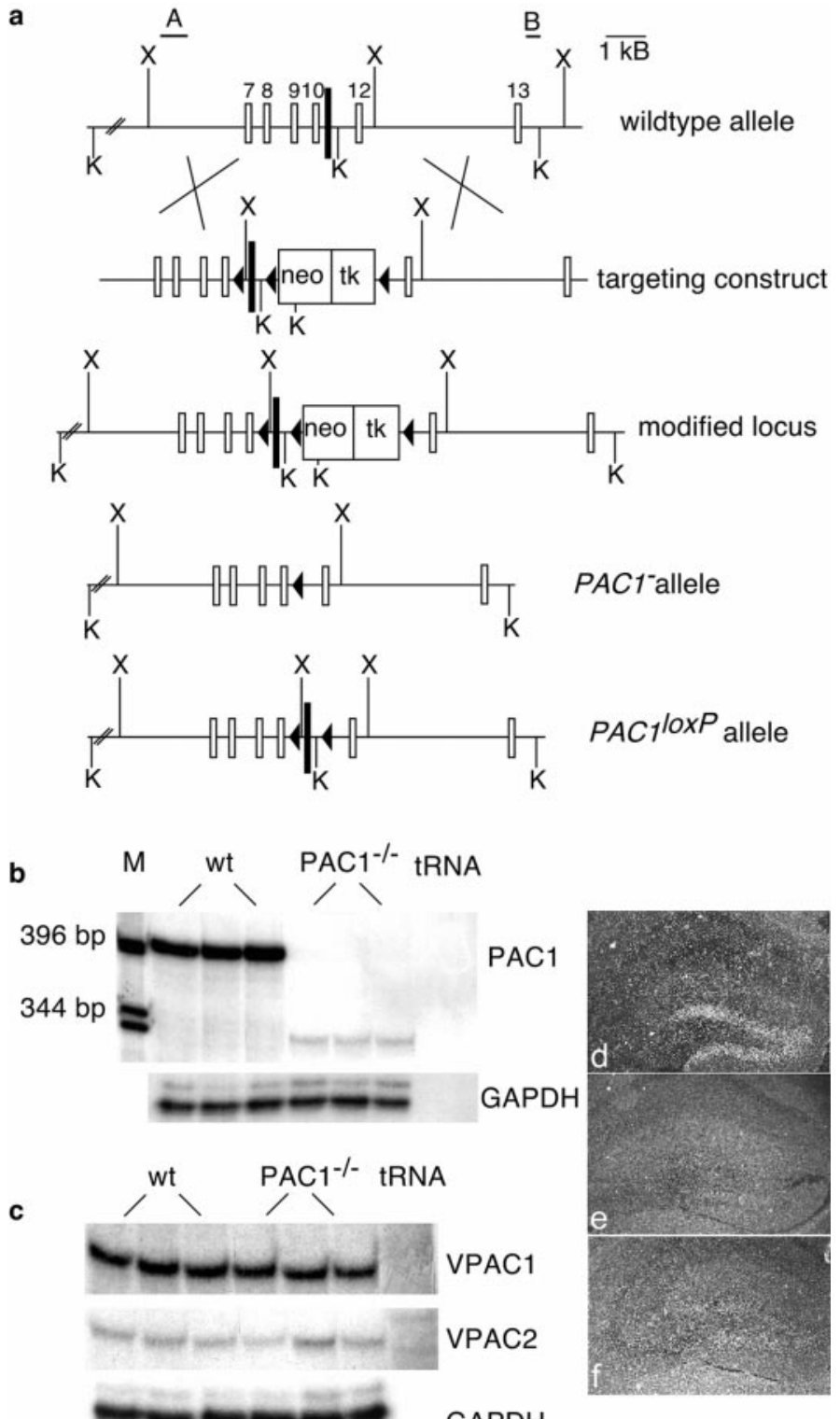

Figure 1. Generation of PAC1-deficient mice. $a$, Organization of PAC1 encompassing exons 7-13. We flanked exon 11 (black box) with loxP sites in two steps. First, we generated the modified allele by homologous recombination in ES cells. Second, transient expression of Cre recombinase led to removal of the selection cassette, generating $\mathrm{PACl}^{-}$and $P A C 1^{\text {loxP }}$ alleles. A scheme of the wild-type locus, the targeting vector, and the resulting alleles is depicted (black triangles, loxP; K, KpnI; X, XbaI; $A$ and $B$ represent probes outside of the homology arms used for Southern blot analysis of electroporated ES cells). $b, c$, RNase protection analysis of total brain RNA from wild-type $(w t)$ and $\mathrm{PAC1}^{-/-}$mice. $b$, Although the 400 bp wild-type transcript is absent in PAC1 $1^{-/-}$brains, a faint $340 \mathrm{bp}$ fragment is detectable, representing an alternatively spliced transcript giving rise to a truncated receptor protein. $c$, PACAP type II receptors (VPAC1 and VPAC2) are not upregulated in PAC1 ${ }^{-/-}$brains $(M, 1 \mathrm{~kb}$ ladder). $\quad d-f, \quad$ In situ hybridization of control, $P A C 1^{-1-}$, and PAC1 ${ }^{\text {CaMKCre2 }}$ brains. In comparison with control $(d)$, PAC1 mRNA is almost completely absent in the hippocampal region of PAC1 ${ }^{\text {CaMKCre2 }}$ brains $(f)$ and also not detectable in PAC1 $1^{-/-}$brains $(e)$.

\section{Impairment of mossy fiber LTP in PAC1-deficient mice}

Because of the strong and restricted expression of PAC1 protein in hippocampal mossy fiber terminals (Otto et al., 1999), we studied first synaptic plasticity at the mossy fiber synapse 

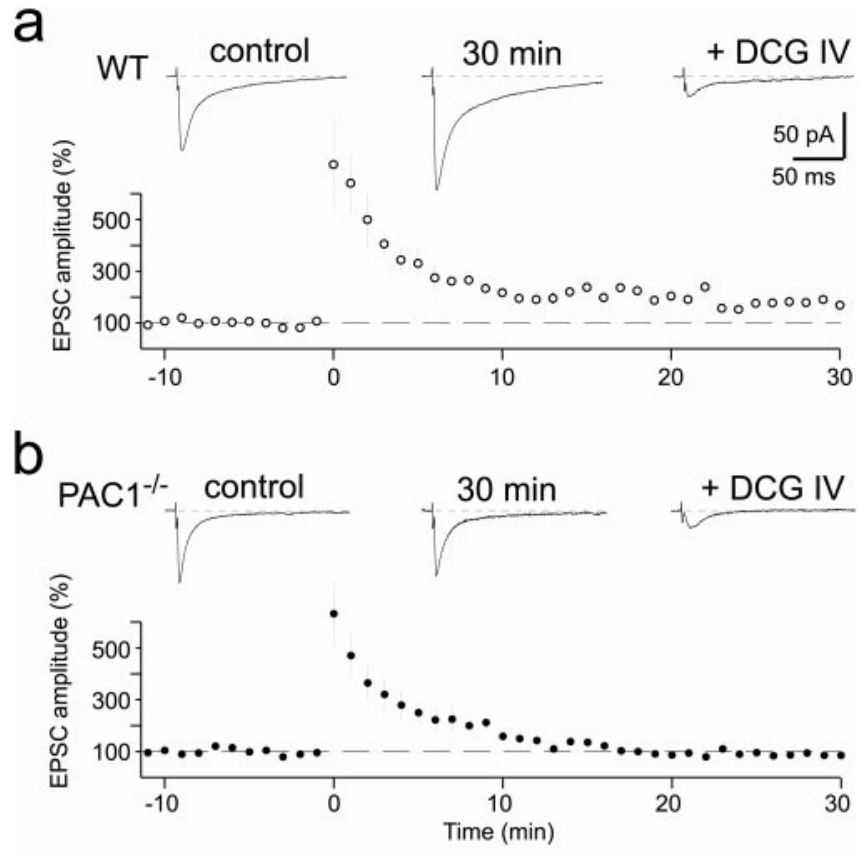

C
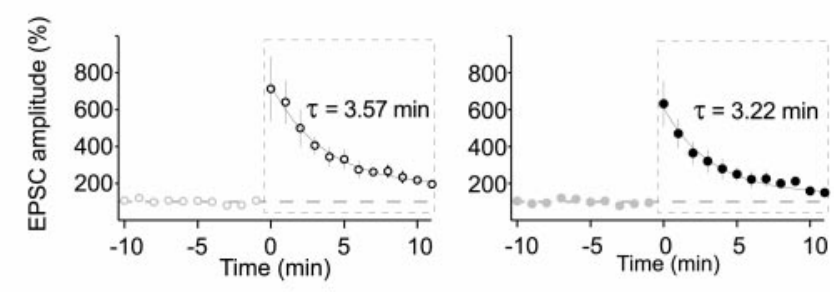

d

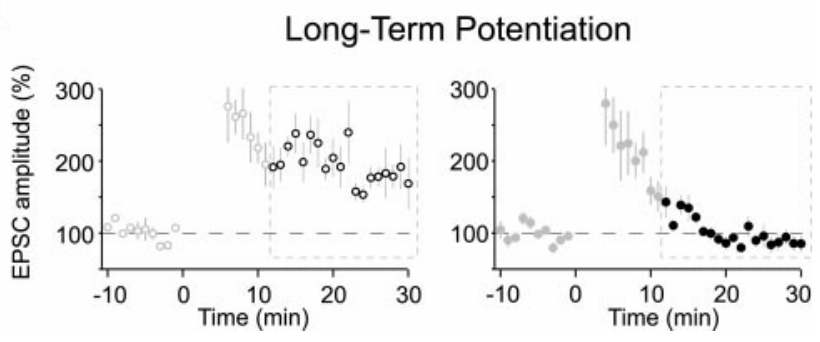

Figure 2. Mossy fiber LTP is impaired in PAC1 $1^{-/-}$mice. $a, b$, LTP summary graphs in wild-type (white circles; mean \pm SEM; 5 cells) and PAC1 ${ }^{-1-}$ (black circles; 7 cells) mice. Insets above show sample traces of EPSCs before (control), $30 \mathrm{~min}$ after tetanization $(30 \mathrm{~min}$ ), and after 1 $\mu \mathrm{M}$ DCG-IV bath application (+DCG IV) in wild-type $(a, W T)$ and $\mathrm{PAC1}^{-/-}\left(b, P A C 1^{-1-}\right)$ mice. LTP was induced by a stimulus train lasting for $5 \mathrm{sec}$ at $25 \mathrm{~Hz}$ that was delivered at time 0 . Each current trace is an average of 9-15 consecutive records. All recordings were done at room temperature $\left(21-25^{\circ} \mathrm{C}\right) . c, d$, Different representation of the graphs shown in $a$ and $b$ to stress the similarity of PTP $(c)$ and the difference in LTP $(d)$ in wild-type and PAC1 ${ }^{-1-}$ mice, respectively. Note that the $y$-axes were scaled differently in $c$ and $d$. The $t w o$ solid lines in $c$ represent exponential fits for the first $10 \mathrm{~min}$ of the decay phase of PTP yielding a time constant of $\tau=3.57 \mathrm{~min}$ (WT, left panel graph) and $\tau=3.22 \mathrm{~min}\left(P A C 1^{-1-}\right.$, right panel graph). All recordings were done at room temperature $\left(21-25^{\circ} \mathrm{C}\right)$.

(Zalutsky and Nicoll, 1990; Yeckel et al., 1999) in wild-type and PAC1-deficient mice. In wild-type animals, a train of highfrequency stimulation produced MF-LTP (Fig. $2 a$ ). Its characteristic features are the initial, strong PTP of the EPSC amplitude (mean EPSC amplitudes reached $710 \pm 350 \%$ of control value; $n=5$; mean $\pm \mathrm{SD}$ ) (Fig. 2a,c, left panel), followed by a sustained component of long-lasting potentiation $(185 \pm 57 \%$ of control value, measured at 25-30 min; $n=5$ ) (Fig. 2a). This MF-LTP lasted for the entire duration of recording, typically $30 \mathrm{~min}$ of recording after the tetanus (Fig. 2a,d, left panel). By contrast, a similar conditioning stimulation applied to MFs of $\mathrm{PAC} 1^{-/-}$ mice, while evoking a similar PTP $(630 \pm 340 \%$ of control; $n=$ 7) (Fig. 2c, right panel), produced in seven of seven cells no long-lasting potentiation (Fig. $2 b$,d, right panel). At $\sim 15 \mathrm{~min}$ after conditioning, the EPSC amplitude returned to the control value and reached $90 \pm 28 \%(n=7)$ of the control amplitude after 25-30 min (Fig. 2b,d, right panel). These results indicate that PAC1 is selectively required for the sustained component of MF-LTP (Fig. $2 d$ ), but not for PTP (Fig. 2c). To ensure that the recorded EPSCs were predominantly caused by mossy fiber LTP, DCG-IV, an agonist of metabotropic glutamate receptors of the group 2/3 subtype (mGluR2/3), was applied to the bath solution (Yokoi et al., 1996; Castillo et al., 1997). DCG-IV (1 $\mu \mathrm{M})$ reduced the amplitude of the EPSC by $60-90 \%$ (Fig. $2 a, b$ ), confirming that the recorded EPSCs were predominantly caused by mossy fiber synapses.

It is important to note that PPF (Salin et al., 1996), another form of short-term potentiation at these synapses, was also not affected (Fig. 3c) [PPF ratio was $209 \pm 54 \%(n=5)$ and $205 \pm$ $67 \%(n=7)$ in wild-type and mutant mice, respectively].

Although the evidence presently available points toward a rather selective presence of PAC1 at mossy fiber terminals (Otto et al., 1999), it seemed nevertheless interesting to test whether deficiency of the receptor interferes with LTP in hippocampal granule cells, the neurons from which mossy fibers originate. For this purpose, we performed whole-cell recordings from visually identified granule cells (Keller et al., 1991) and stimulated perforant path fibers. Long-term potentiation at synapses formed between perforant path fibers and granule cells (PP-LTP) occurred in both wild-type (142 $\pm 27 \%$ of control, measured $40 \mathrm{~min}$ after conditioning; $n=6)$ and mutant mice $(130 \pm 29 \%$ of control; $n=6$ ) (Fig. 3a,b). This intracellularly recorded LTP was very similar to that recorded extracellularly by other investigators (Lynch et al., 1985; Hanse and Gustafsson, 1992). The mean level of potentiation in $\mathrm{PAC1}{ }^{-/-}$mice seemed to be somewhat smaller than in wild-type mice (Fig. 3a), however, the difference was not statistically significant (Student's $t$ test; $p>0.1$ ). Thus, taken together, the results of our cellular analyses clearly demonstrate that impairment of LTP in PAC1-deficient mice occurs predominantly at mossy fiber buttons, the only site at which PAC1 has been detected immunohistochemically in the hippocampus (Otto et al., 1999).

\section{Associative but not declarative learning is impaired in PAC1-deficient mice}

Because PAC1-deficient mice display a strong impairment of mossy fiber LTP, we investigated whether learning and memory is also impaired in these mouse mutants. We first analyzed mutants of both lines in two hippocampus-dependent tasks that model declarative learning and memory, the Morris water maze (Fig. $4 a, b)$ and the social transmission of food preference (Fig. 4c). Neither PAC1 ${ }^{-/-}$nor PAC1 ${ }^{\mathrm{CaMKCre} 2}$ mice (data not shown) exhibit any deficits in these learning paradigms (Fig. 4b,c). During the acquisition phase, wild-type and mutant animals learn to search for the platform, as evidenced by the reduction of time needed to find the platform at the end of the training phase (Fig. $4 a$ ). During the probe trial of the Morris water maze, mutant and 
a
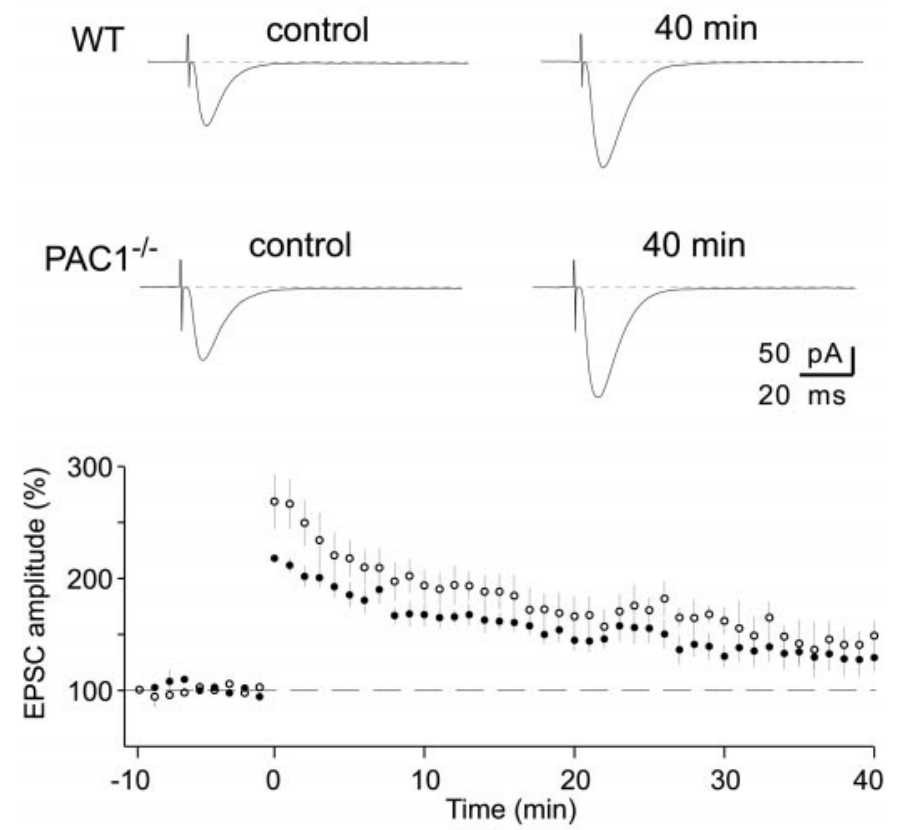

b

C
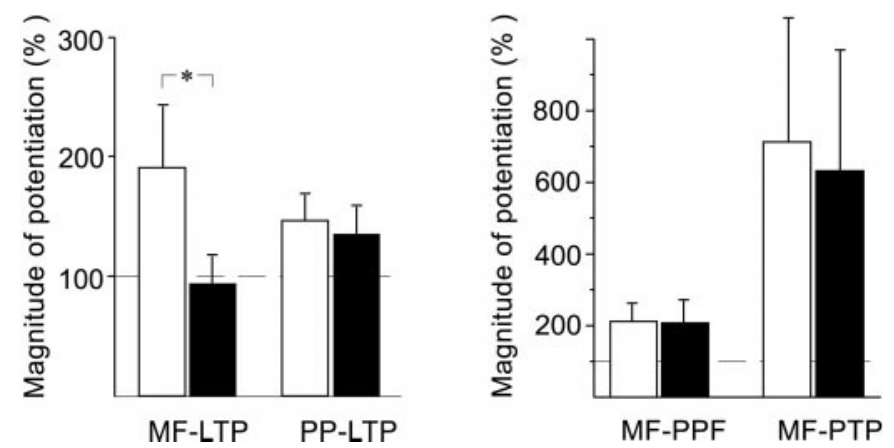

Figure 3. Preservation of LTP at the perforant path synaptic inputs to hippocampal granule cells in PAC1 $1^{-/-}$mice. $a$, LTP summary graph in wild-type (white circles; mean $\pm \mathrm{SEM} ; 6$ cells) and $\mathrm{PAC1}{ }^{-1}$ (black circles; 6 cells) mice. Inset illustrates sample EPSC traces before (control) and $40 \mathrm{~min}$ after LTP induction (40 min) in wild-type (WT, top traces) and $\mathrm{PAC1} 1^{-1-}\left(\mathrm{PAC1}^{-/-}\right.$, bottom traces $)$mice. Each current trace is an average of $9-15$ consecutive records. LTP was induced by five $100 \mathrm{msec}$ lasting stimulation trains at $100 \mathrm{~Hz}$ separated by $15 \mathrm{sec}$ intervals, while the cell was current-clamped at $-50 \mathrm{mV}$. Recordings were done at $30-32^{\circ} \mathrm{C}$. $b$, Summary graph (mean $\pm \mathrm{SD}$ ) of the magnitude of LTP in wild-type (white bars) and $\mathrm{PAC} 1^{-/}$(black bars) mice examined in mossy fiber to CA3 pyramidal cell synapses ( $M F-L T P$, from data shown in Fig. $2 a, b)$ and lateral perforant path to granule cell synapse ( $P P-L T P$, from data shown in Fig. 3a). A significant change was observed only for MF-LTP $\left({ }^{*} p<\right.$ 0.001). MF-LTP was measured at room temperature $\left(21-25^{\circ} \mathrm{C}\right)$, whereas PP-LTP was measured at $30-32^{\circ} \mathrm{C}$ (see Materials and Methods). $c$, Summary graph (mean $\pm \mathrm{SD}$ ) of the magnitude of paired-pulse facilitation (MF-PPF) and post-tetanic potentiation $(M F-P T P)$ at mossy fiber to CA3 pyramidal cell synaptic inputs from wild-type (white bars; $n=5$ ) and PAC1 ${ }^{-1-}$ (black bars; $n=7$ ) mice. There was no significant difference between wild-type and mutant mice. Recordings were done at room temperature $\left(21-25^{\circ} \mathrm{C}\right)$.

wild-type animals searching for the platform spent significantly more time in the trained quadrant than in the other three quadrants, indicating that both groups have learned and remember the old platform position equally well (Fig. $4 b$ ). There are also no $\mathbf{a}$
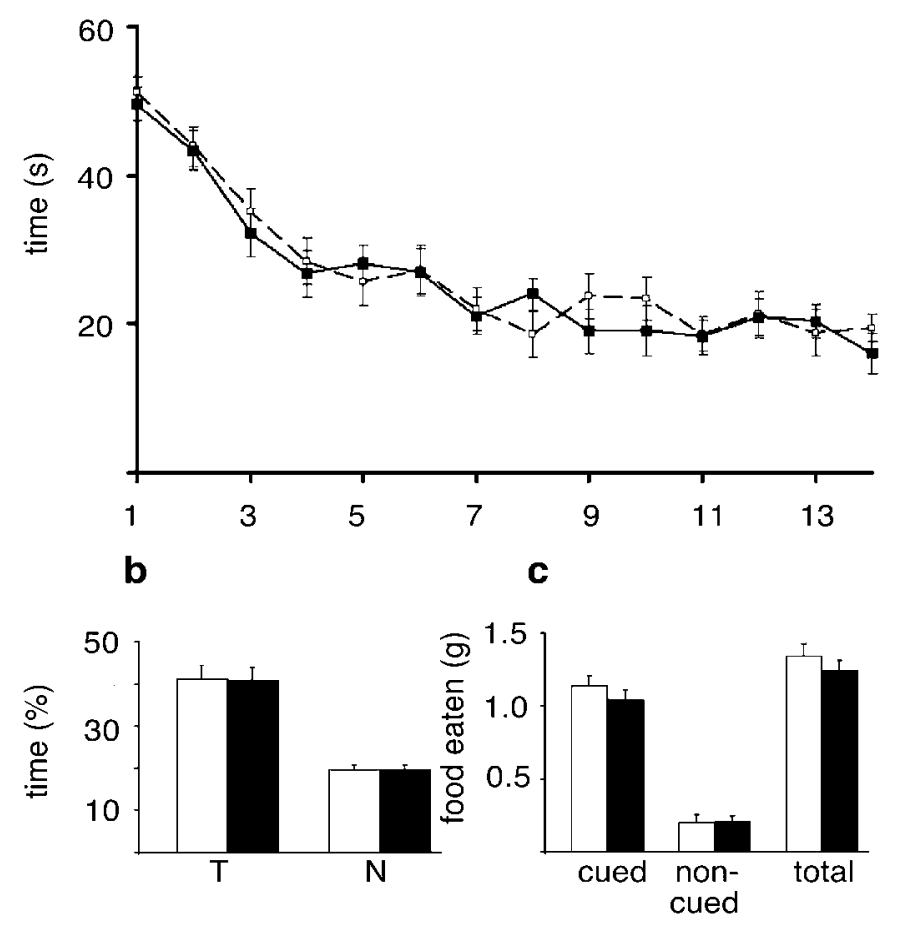

Figure 4. $\mathrm{PAC1}^{-/-}$mice do not display any memory deficits in declarative learning tasks. $a$, Acquisition phase of the Morris water maze. The average values of two daily trials over a training period of 2 weeks are depicted. Wild-type $(n=28$; broken line $)$ and $\mathrm{PAC1}^{-/-}(n=28$; solid line) as well as PAC1 $1^{\text {CaMKCre2 }}$ mice (data not shown) learn the task equally well, as evidenced by the reduction of time needed to find the platform at the end of the training period. $b$, Probe trial of the Morris water maze. Wild types (white bars) and mutants (black bars) have learned and remember the old platform position equally well. In search of the platform, they spend significantly more time in the trained quadrant $(T)$ than on average in the other three quadrants $(N)$. $c$, Social transmission of food preference. PAC1 $1^{-1-}$ as well as PAC1 $1^{\text {CaMKCre2 }}$ mice (data not shown) do not display any memory deficits in the social transmission of food preference. Mutants $(n=28$; black bars $)$ and wild types $(n=28$; white bars) eat significantly more of the cued than of the non-cued food and thus remember exactly the food eaten by the demonstrator mouse 24 hr before.

deficits in the social transmission of food preference; mutants and wild-type animals eat significantly more of the cued than of the non-cued food, indicating that they remember exactly the food eaten by the demonstrator mouse $24 \mathrm{hr}$ before (Fig. $4 c$ ).

Motivated by the finding that Drosophila carrying a mutation in the PACAP-related gene amnesiac display associative learning deficits (Quinn et al., 1979), we next analyzed the mice in a nondeclarative, associative learning paradigm, i.e., fear conditioning. For the interpretation of the results, it is noteworthy that in the conditioning chambers mutant mice of both strains showed comparable preshock locomotor activities to their wild-type littermates (PAC1 ${ }^{\mathrm{CaMKCre} 2}$ line: mutants, $585 \pm 34.6$; wild types, $584 \pm 42$ activity counts; $p=0.98$; PAC $1^{-/-}$line: mutants, $561 \pm$ 25.7; wild types, $520 \pm 33.3$ activity counts; $p=0.34)$. $\mathrm{PAC1}^{-/-}$ as well as $\mathrm{PAC} 1^{\mathrm{CaMKCre} 2}$ mice show a drastic reduction of the freezing response in the long-term test of contextual fear conditioning (Fig. 5), which is thought to be hippocampus- and amygdala-dependent (Kim and Fanselow, 1992; Philips and LeDoux, 1992; Maren and Fanselow, 1996). After reexposure into the cage where conditioning had taken place $24 \mathrm{hr}$ before, wild- 


\section{Fear conditioning (24 hour test)}

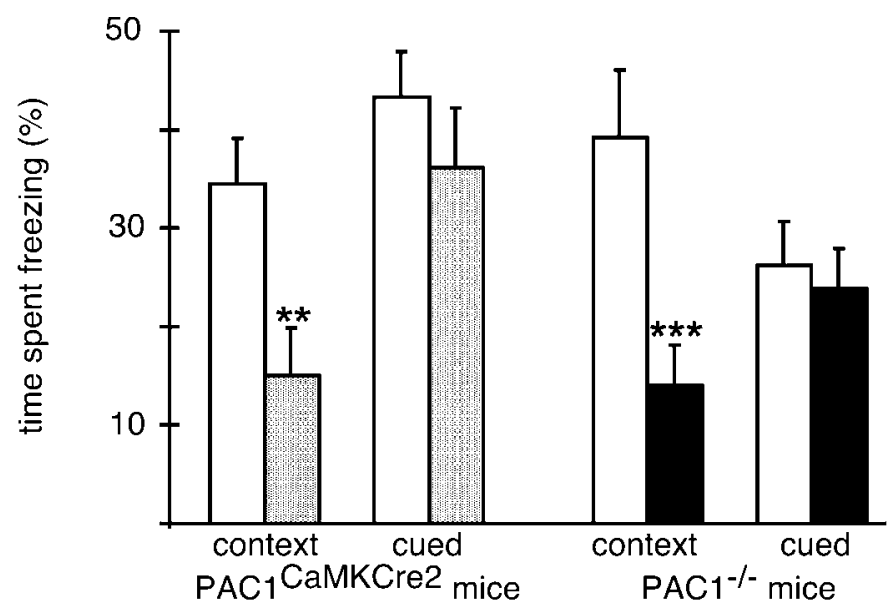

Figure 5. PAC1 ${ }^{-1-}$ and $\mathrm{PAC} 1^{\mathrm{CaMKCre} 2}$ mice show a selective deficit in hippocampus-dependent associative learning. PAC1 ${ }^{-/-}$mice $[n=14$ mutants (black bars), 14 wild types (white bars); $p<0.005$ ] as well as PAC1 ${ }^{\text {CaM KCre2 }}$ mice $[n=12$ mutants (gray bars), 20 wild types (white bars); $p<0.01$ ] exhibit a strongly reduced freezing response in contextual but not cued fear conditioning (24 hr test).

type animals remembered the contextual environment and showed a strong freezing response, whereas mutants of both lines started to explore the cage as if they had never seen it before. However, both mutant mouse lines did not show any deficits in the long-term test of cued fear conditioning (Fig. 5), a test that is thought to be amygdala-dependent (Kim and Fanselow, 1992; Philips and LeDoux, 1992; Maren and Fanselow, 1996). Mutants of both mouse lines showed in response to the tone a very similar freezing behavior as their wild-type littermates (Fig. 5). These findings clearly demonstrate a crucial role for PAC1-mediated signaling in associative, but not declarative, learning processes.

\section{DISCUSSION}

In this study, we investigated the potential role of PAC1-mediated signaling in synaptic plasticity as well as its impact on learning and memory. We used the Cre/loxP recombination system (Gu et al., 1994) to generate two different mutant mouse strains on the same genetic background. For the first time, we present evidence that PAC1 is involved in synaptic plasticity at the mossy fiber synapse and in associative learning. The generation of a conditional and a complete knock-out mouse line on the same genetic background allows direct comparison of both mouse lines and may circumvent developmental effects that often hamper analysis of conventional mouse knock-out models. In our conditional mouse line, PAC1 is inactivated postnatally in cortical forebrain areas and the hippocampus.

In parallel to our study, two different conventional PAC1deficient mouse strains have been developed, but they have not been analyzed in learning paradigms (Hashimoto et al., 2000; Jamen et al., 2000).

\section{A role of PAC1-mediated signaling for hippocampus- dependent associative learning and memory}

As evidenced by the probe trial of the Morris water maze and the social transmission of food preference, both mutant mouse lines do not display any deficits in declarative learning tasks. Because hippocampal expression of $P A C 1$ is restricted to the mossy fiber synapse (Otto et al., 1999), the absence of spatial learning deficits (Morris water maze) and the absence of LTP impairment at the Schaffer collateral (Hashimoto et al., 2000) in the mutant mice is not surprising. In contrast to the Schaffer collateral pathway, the mossy fiber synapse seems to be less important for spatial learning (Chen and Tonegawa, 1997). Large parts of information are likely to be transmitted directly from the entorhinal cortex to pyramidal cells of CA3 and CA1, bypassing the mossy fiber synapse and not following the traditional trisynaptic circuit (Yeckel and Berger, 1990). The pivotal role of the Schaffer collateral for spatial learning is further evidenced by gene knock-out models of CaMKII $\alpha$ (Silva et al., 1992), fyn (Grant et al., 1992), and PKC $\gamma$ (Abeliovich et al., 1993), which all lead to an impairment of Schaffer collateral LTP and deficits in spatial learning.

Whereas declarative learning remains unaffected, both mutant mouse lines show a selective impairment of associative learning, i.e., contextual fear conditioning. This finding is very exciting because Drosophila harboring a mutation in the PACAP-related gene amnesiac display also associative learning deficits (Quinn et al., 1979). Therefore, the extreme evolutionary conservation of the neuropeptide PACAP and its type I receptor PAC1 may parallel their implication in a phylogenetically old learning paradigm, i.e., associative learning. Meanwhile, many components of the neuronal pathways involved in fear conditioning are known (Maren and Fanselow, 1996). The basolateral complex of the amygdala seems to be the putative locus for the association of the conditioned (tone, context) and unconditioned (footshock) stimulus. Sensory information is conveyed via two distinct inputs to the basolateral amygdala complex. Whereas auditory stimuli are processed to the amygdala via the medial geniculate nucleus of the thalamus, contextual stimuli reach the amygdala via the hippocampal formation. The basolateral complex of the amygdala projects to the central nucleus, which is connected with several brain areas involved in the generation of fear responses, such as the lateral hypothalamus (increase of blood pressure) or the periaqueductal gray (freezing response) (Maren and Fanselow, 1996). With regard to this pathway, lesions of the amygdala or the periaqueductal gray lead to an impairment of the freezing response in contextual as well as cued fear conditioning (Liebman et al., 1970; Campeau and Davis, 1995). Lesions of the hippocampus lead to impaired contextual but do not affect cued fear conditioning (Kim and Fanselow, 1992; Philips and LeDoux, 1992; Maren and Fanselow, 1996). The hippocampus is known to play within a critical time window a crucial role for the consolidation of contextual fear into long-term memory (Kim and Fanselow, 1992; Anagnostaras et al., 1999). Because mutants of both mouse lines display a dissociation between intact cued but impaired contextual fear conditioning, we conclude in accordance with the existing model of fear conditioning (Maren and Fanselow, 1996) that this phenotype reflects a hippocampusdependent learning deficit. Importantly, an extensive neurological examination did not reveal any evidence for deficits of the sensory afferents necessary for processing contextual information. Furthermore, neither the Morris water maze task (vision) nor the social transmission of food preference (olfaction) revealed any deficits. Finally, because freezing in response to the tone was also not affected, the fear conditioning pathway in the amygdala and downstream of the amygdala must be intact (Maren and Fanselow, 1996).

Thus, we conclude that PAC1-mediated signaling in the hippocampus is required for contextual fear conditioning. In direct support of this view, we found that the brain regions with a 
complete inactivation of $P A C 1$ in $P A C 1^{-1-}$ as well as $\mathrm{PAC} 1{ }^{\mathrm{CaMKCre} 2}$ mice are the dentate gyrus and neocortical areas of the forebrain, but not the amygdala or the periaqueductal gray. In these latter regions $P A C 1$ is only inactivated in $\mathrm{PAC} 1^{-/-}$but not PAC1 ${ }^{\mathrm{CaMKCre} 2}$ mice. Because lesions of the neocortex do not impair contextual fear conditioning (Philips and LeDoux, 1992; Chen et al., 1996), PAC1-mediated signaling in the hippocampus seems to play the critical role for the consolidation of contextual fear into long-term memory.

\section{PAC1 is a novel determinant of synaptic plasticity at the mossy fiber synapse}

The immunohistochemical data (Otto et al., 1999) and the electrophysiological results provide strong evidence that, within the hippocampus, the mossy fiber terminals represent the predominant site of PAC1-mediated signaling. At the mossy fiber synapse, LTP is distinctly different from LTP at all other hippocampal synapses. It is NMDA receptor-independent, and its induction requires an increase in the presynaptic calcium level (Nicoll and Malenka, 1995) and, under certain conditions, also postsynaptic calcium signaling (Yeckel et al., 1999). Although the molecular mechanism for LTP at the mossy fiber synapse is not known yet, there is strong evidence that the presynaptic calcium increase activates adenylate cyclases (Huang et al., 1994; Weisskopf et al., 1994). It has been hypothesized that activated adenylate cyclase type 1 (AC1) leads to an activation of PKA, which could cause an enhanced glutamate release by phosphorylation of proteins that influence the secretory machinery (Trudeau et al., 1996; Villacres et al., 1998). Rab3A is one of those candidates that contribute to PKA-mediated neurotransmitter release (Geppert et al., 1994). Within the hippocampus, PAC1 protein is exclusively expressed presynaptically in mossy fiber terminals (Otto et al., 1999). PAC1 can elevate intracellular calcium levels and activate PKA, two mechanisms, which were shown to determine long-term neuronal plasticity at the mossy fiber synapse (Huang et al., 1994; Weisskopf et al., 1994; Nicoll and Malenka, 1995). It is important to note that neither short-term synaptic plasticity at the mossy fiber synapse nor perforant path LTP were significantly impaired in the mutant mice. Similar results were previously obtained in Rab3A (Castillo et al., 1997) and AC1-deficient mice (Villacres et al., 1998). These findings are remarkable for two reasons: first, together with Rab3A knock-out mice (Castillo et al., 1997), PAC1-deficient mice are the first in vivo models that support the presynaptic locus of mossy fiber LTP expression. Second, the observed changes of neuronal plasticity at the mossy fiber synapse are identical with those seen in Rab3A (Castillo et al., 1997) and AC1-deficient mice (Villacres et al., 1998), which suggests that PAC1 may act in the same cascade upstream of AC1 and Rab3A activation. In conclusion, our findings identify a new mechanism through which PAC1 mediates neuronal signaling. PAC1mediated signaling within the hippocampus seems to be largely restricted to mossy fiber terminals. Our results suggest that PAC1, through its involvement in a presynaptic form of hippocampal LTP, determines an associative form of hippocampal learning.

\section{REFERENCES}

Abeliovich A, Paylor R, Chen C, Kim JJ, Wehner JM, Tonegawa S (1993) PKC $\gamma$ mutant mice exhibit mild deficits in spatial and contextual learning. Cell 75:1263-1271.

Anagnostaras SG, Maren S, Fanselow MS (1999) Temporally graded retrograde amnesia of contextual fear after hippocampal damage in rats: within-subjects examination. J Neurosci 19:1106-1114.

Arimura A (1998) Perspectives on pituitary adenylate cyclase activating polypeptide (PACAP) in the neuroendocrine, endocrine, and nervous systems. Jpn J Physiol 48:303-331.

Bliss TVP, Collingridge GL (1993) A synaptic model of memory: longterm potentiation in the hippocampus. Nature 361:31-39.

Campeau S, Davis M (1995) Involvement of the central nucleus and basolateral complex of the amygdala in fear conditioning measured with fear-potentiated startle in rats trained concurrently with auditory and visual conditioned stimuli. J Neurosci 15:2301-2311.

Castillo PE, Janz R, Südhof TC, Tzounopoulos T, Malenka RC, Nicoll RA (1997) Rab3A is essential for mossy fiber long-term potentiation in the hippocampus. Nature 388:590-593.

Chen C, Tonegawa S (1997) Molecular genetic analysis of synaptic plasticity, activity-dependent neural development, learning, and memory in the mammalian brain. Annu Rev Neurosci 20:157-184.

Chen C, Kim JJ, Thompson RF, Tonegawa S (1996) Hippocampal lesions impair contextual fear conditioning in two strains of mice. Behav Neurosci 110:1177-1180.

Christophe J (1993) Type I receptors for PACAP (a neuropeptide even more important than VIP?). Biochem Biophys Acta 1154:183-199.

Claiborne BJ, Xiang Z, Brown TH (1993) Hippocampal circuitry complicates analysis of long-term potentiation in mossy fiber synapses. Hippocampus 3:115-121.

Gass P, Wolfer DP, Balschun D, Rudolph D, Frey U, Lipp HP, Schütz G (1998) Deficits in memory tasks of mice with CREB mutations depend on gene dosage. Learn Mem 5:274-288.

Geppert M, Bolshakov VY, Siegelbaum SA, Takei K, De Camilli P, Hammer RE, Sudhof TC (1994) The role of Rab3A in neurotransmitter release. Nature 369:493-497.

Grant SG, O’Dell TJ, Karl KA, Stein PL, Soriano P, Kandel ER (1992) Impaired long-term potentiation, spatial learning, and hippocampal development in fyn mutant mice. Science 258:1903-1910.

Gu H, Marth JD, Orban PC, Mossmann H, Rajewski K (1994) Deletion of a DNA polymerase $\beta$ gene segment in T cells using cell type-specific gene targeting. Science 265:103-106.

Hanse E, Gustafsson B (1992) Postsynaptic, but not presynaptic, activity controls the early time course of long-term potentiation in the dentate gyrus. J Neurosci 12:3226-3240.

Hashimoto H, Nogi H, Mori K, Ohishi H, Shigemoto R, Yamamoto K, Matsuda T, Mizuno N, Nagata S, Baba A (1996a) Distribution of the mRNA for a pituitary adenylate cyclase-activating polypeptide receptor in the rat brain: an in situ hybridization study. J Comp Neurol 371:567-577.

Hashimoto H, Yamamoto K, Hagigara N, Ogawa N, Nishino A, Aino H, Nogi H, Imanishi K, Matsuda T, Baba A (1996b) cDNA cloning of a mouse pituitary adenylate cyclase-activating polypeptide receptor. Biochim Biophys Acta 1281:129-133.

Hashimoto H, Shintani N, Nishino A, Okabe M, Ikawa M, Matsuyama S, Itoh K, Yamamoto K, Tomimoto S, Fujita T, Hagihara N, Mori W, Koyama Y, Matsuda T, Nagata S, Baba A (2000) Mice with markedly reduced PACAP (PAC1) receptor expression by targeted deletion of the signal peptide. J Neurochem 75:1810-1817.

Huang YY, Li XC, Kandel ER (1994) cAMP contributes to mossy fiber LTP by initiating both a covalently-mediated early phase and macromolecular synthesis-dependent late phase. Cell 79:69-79.

Inagaki N, Yoshida H, Mizuta M, Mizuno N, Fujii Y, Gonoi T, Miyazaki J, Seino S (1994) Cloning and functional characterization of a third pituitary adenylate cyclase-activating polypeptide receptor subtype expressed in insulin-secreting cells. Proc Natl Acad Sci USA 91:2679-2683.

Ishihara T, Shigemoto R, Mori K, Takahashi K, Nagata S (1992) Functional expression and tissue distribution of a novel receptor for vasoactive intestinal polypeptide. Neuron 8:811-819.

Jamen F, Persson K, Bertrand G, Rodriguez-Henche N, Puech R, Bockaert J, Ahren B, Brabet P (2000) PAC1 receptor-deficient mice display impaired insulinotropic response to glucose and reduced glucose tolerance. J Clin Invest 105:1307-1315.

Johnson MC, Mc Cormack RJ, Delgado M, Martinez C, Ganea D (1996) Murine T-lymphocytes express vasoactive intestinal peptide receptor I (VIP-RI) mRNA. J Neuroimmunol 68:109-119.

Kaestner KH, Hiemisch H, Luckow B, Schütz G (1994) The HNF-3 gene family of transcription factors in mice: gene structure, cDNA sequence and mRNA distribution. Genomics 20:377-385.

Kellendonk C, Tronche F, Casanova E, Anlag K, Opherk C, Schütz G (1999) Inducible site-specific recombination in the brain. J Mol Biol 285:175-182.

Keller BU, Konnerth A, Yaari Y (1991) Patch clamp analysis of excitatory synaptic currents in granule cells of rat hippocampus. J Physiol (Lond) 435:275-293.

Kim JJ, Fanselow MS (1992) Modality-specific retrograde amnesia of fear. Science 256:675-677.

Liebman JM, Mayer DJ, Liebeskind JC (1970) Mesencephalic central gray lesions and fear-motivated behaviour in rats. Brain Res 23:353-370.

Lutz EM, Sheward WJ, West KM, Morrow JA, Fink G, Harmar AJ (1993) The $\mathrm{VIP}_{2}$ receptor: molecular characterization of a cDNA 
encoding a novel receptor for vasoactive intestinal peptide. FEBS Lett 334:3-8.

Lynch MA, Errington ML, Bliss TV (1985) Long-term potentiation of synaptic transmission in the dentate gyrus: increased release of $\left[{ }^{14} \mathrm{C}\right]$ glutamate without increase in receptor binding. Neurosci Lett 62:123-129.

Maren S, Fanselow SM (1996) The amygdala and fear conditioning: has the nut been cracked? Neuron 16:237-240.

Milner B, Squire LR, Kandel ER (1998) Cognitive neuroscience and the study of memory. Neuron 20:445-468.

Nicoll RA, Malenka RC (1995) Contrasting properties of two forms of long-term potentiation in the hippocampus. Nature 377:115-118.

Otto C, Zuschratter W, Gass P, Schütz G (1999) Presynaptic localization of the PACAP-type-I-receptor in hippocampal and cerebellar mossy fibers. Mol Brain Res 66:163-174.

Philips RG, LeDoux JE (1992) Differential contribution of amygdala and hippocampus to contextual and cued fear conditioning. Behav Neurosci 106:274-285.

Quinn WG, Sziber PP, Booker R (1979) The Drosophila memory mutant amnesiac. Nature 277:212-214.

Salin PA, Scanziani M, Malenka RC, Nicoll RA (1996) Distinct shortterm plasticity at two excitatory synapses in the hippocampus. Proc Natl Acad Sci USA 93:13304-13309.

Shivers BD, Gorcs TJ, Gottschall PE, Arimura A (1991) Two high affinity binding sites for pituitary adenylate cyclase activating polypeptide have different tissue distribution. Endocrinology 128:3055-3065.

Silva AJ, Paylor R, Wehner JM, Tonegawa S (1992) Impaired spatial learning in $\alpha$-calcium-calmodulin kinase II mutant mice. Science 257:206-211.

Swanson LW, Teyler TJ, Thompson RF (1982) Hippocampal long-term potentiation: mechanisms and implications for memory. Neurosci Res Prog Bull 20:613-768.

Trudeau LE, Emery DG, Haydon PG (1996) Direct modulation of the secretory machinery underlies PKA-dependent synaptic facilitation in hippocampal neurons. Neuron 17:789-797.

Villacres EC, Wong ST, Chavkin C, Storm DR (1998) Type I adenylyl cyclase mutant mice have impaired mossy fiber long-term potentiation. J Neurosci 18:3186-3194.

Weisskopf MG, Castillo PE, Zalutsky RA, Nicoll RA (1994) Mediation of hippocampal mossy fiber long-term potentiation by cyclic AMP. Science 23:1878-1882.

Yeckel MF, Berger TW (1990) Feedforward excitation of the hippocampus by afferents from the entorhinal cortex: redefinition of the role of the trisynaptic pathway. Proc Natl Acad Sci USA 87:5832-5836.

Yeckel MF, Kapur A, Johnston D (1999) Multiple forms of LTP in hippocampal CA3 neurons use a common postsynaptic mechanism. Nat Neurosci 2:625-633.

Yokoi M, Kobayashi K, Manabe T, Takahashi T, Sakaguchi I, Katsuura G, Shigemoto R, Ohishi H, Nomura S, Nakamura K, Nakoa K, Katsuki M, Nakanishi S (1996) Impairment of hippocampal mossy fiber LTD in mice lacking mGluR2. Science 273:645-647.

Zalutsky RA, Nicoll RA (1990) Comparison of two forms of long-term potentiation in single hippocampal neurons. Science 248:1619-1624. 